\title{
Composition, anti-quorum sensing and antimicrobial activity of essential oils from Lippia alba
}

\author{
Jesus Olivero-Verbel ${ }^{1}$, Ana Barreto-Maya ${ }^{1}$, Angela Bertel-Sevilla ${ }^{1}$, Elena E. Stashenko ${ }^{2}$ \\ ${ }^{1}$ Environmental and Computational Chemistry Group, College of Pharmaceutical Sciences, \\ University of Cartagena, Cartagena, Colombia. \\ ${ }^{2}$ Chromatography Laboratory, Research Centre for Biomolecules, Industrial University of Santander, \\ Bucaramanga, Colombia.
}

Submitted: October 4, 2012; Approved: March 14, 2014.

\begin{abstract}
Many Gram-negative pathogens have the ability to produce $\mathrm{N}$-acylhomoserine lactones (AHLs) as signal molecules for quorum sensing (QS). This cell-cell communication system allows them to coordinate gene expression and regulate virulence. Strategies to inhibit QS are promising for the control of infectious diseases or antibiotic resistant bacterial pathogens. The aim of the present study was to evaluate the anti-quorum sensing (anti-QS) and antibacterial potential of five essential oils isolated from Lippia alba on the Tn-5 mutant of Chromobacterium violaceum CV026, and on the growth of the gram-positive bacteria $S$. aureus ATCC 25923. The anti-QS activity was detected through the inhibition of the QS-controlled violacein pigment production by the sensor bacteria. Results showed that two essential oils from $L$. alba, one containing the greatest geranial:neral and the other the highest limonene:carvone concentrations, were the most effective QS inhibitors. Both oils also had small effects on cell growth. Moreover, the geranial/neral chemotype oil also produced the maximum zone of growth inhibition against $S$. aureus ATCC 25923. These data suggest essential oils from L. alba have promising properties as QS modulators, and present antibacterial activity on $S$. aureus.
\end{abstract}

Key words: violacein, Chromobacterium violaceum, limonene, carvone, geranial, neral.

\section{Introduction}

The increasing rate of multi-drug-resistant pathogenic bacteria drastically reduced the efficiency of conventional antibiotics. This multi-drug resistance is now recognized as a global health problem (Sipahi, 2008; Köhler et al., 2010; Chong et al., 2011), as many pathogens have the ability to develop antimicrobial resistance through different mechanisms, including random mutations, and the dissemination and interchange of antibiotic resistance genes between diverse pathogenic bacteria (Issac Abraham et al., 2011; Kaufman, 2011). Thus, there is a pressing need for the development of novel therapeutic measures to prevent infection among drug-resistant bacterial pathogens (Musthafa et al., 2010).

A promising approach is to target bacterial cell-tocell communication, commonly known as quorum sensing
(QS). This is a process that bacteria use to sense information from other cells. The "language" utilized for this intercellular communication is mediated by extracellular signaling molecules called autoinducers (AIs), which accumulate in the environment in proportion to cell density (Kabir et al., 2010; Yang et al., 2010; Deep et al., 2011; May et al., 2011; Krishnan et al., 2012). Many physiological processes in the bacteria including luminescence, virulence, motility, sporulation, biofilm formation, development of genetic competence, production of secreted proteolytic enzymes, synthesis of peptide antibiotics and fluorescence are coordinated by QS (Singh et al., 2009; Truchado et al., 2009; Rocha-Estrada et al., 2010).

In general, each bacteria species produces and responds to a unique autoinducer signal. Gram-negative and Gram-positive bacteria use acylated homoserine lactones (AHLs) and oligopeptides as autoinducers, respectively

Send correspondence to J. Olivero-Verbel. Environmental and Computational Chemistry Group, College of Pharmaceutical Sciences, University of Cartagena, Zaragocilla Campus, Cartagena, Colombia. E-mail: joliverov@unicartagena.edu.co, jesusolivero@yahoo.com. 
(Xavier and Bassler, 2003). Modulation of the physiological processes controlled by AHLs occurs according to cell density and growth phase; this situation induces expression of QS genes (Whitehead et al., 2001). The central components of AHL-driven QS systems are typically members of the LuxI and LuxR protein families. The first one generates homoserine lactones (AHLs), and the second protein family activates or represses the transcription of specific genes, e.g. the expression of virulent genes (Xavier and Bassler, 2003; Williams et al., 2007; Morohoshi et al., 2008) in bacterial pathogens such as Pseudomonas aeruginosa, Burkholderia cepacia, Salmonella typhimurium, Yersinia enterocolitica, among others; helping these cells to succeed during host infection (Khan et al., 2009; Musthafa et al., 2010). The interruption of this communication system can attenuate microbial virulence because many important human pathogens depend on QS signaling systems to coordinate expression of virulence genes (Zhang and Dong, 2004; Vattem et al., 2007; Jaramillo-Colorado et al., 2011; Siddiqui et al., 2012). Strategies designed to interfere with these signaling systems will likely have broad applicability in the biological control of QS-dependent bacterial infections (Truchado et al., 2009; Ditu et al., 2011).

The importance of QS during bacterial pathogenesis has motivated research of inhibition of this mechanism through the use of anti-QS compounds (Choo et al., 2006). These approaches provide the advantage of interfere with this communication system and control the infectious bacteria without halting their growth, thus avoiding the development of bacterial resistance to antibiotics (Debler et al., 2007; Truchado et al., 2009; Christiaen et al., 2011). The process of inactivation or degradation of QS signal molecules (AHL) is called QS inhibition or quorum quenching (QQ). QQ can be achieved in several ways such as through the enzymatic destruction of QS signal molecules, the development of antibodies to QS signal molecules or via agents which block QS (Chan et al., 2011).

Halogenated furanones produced by the benthic marine macroalga Delisea pulchra were the first identified anti-QS compounds, for their role in inhibiting biofilm (Teplitski et al., 2000; Choo et al., 2006). Subsequently, other plant-derived anti-QS compounds such as oroidin, ursolic acid, naringenin, cinnamaldehyde, salicylic acid, methyl eugenol, and extracts from garlic and edible fruits, have shown antibiofilm properties against several pathogens (Issac Abraham et al., 2011). In this group, essential oils derived from medicinal and food plants have attracted widespread interest in the search of microbial control alternatives. However, these oils, a rich source of diverse bioactive compounds, have been little studied to ascertain their anti-QS activity (Khan et al., 2009). In this context, the present study was carried out to evaluate the anti-QS activity and cytotoxicity of essential oils from Lippia alba, using the bacteria Chromobacterium violaceum CV026.

\section{Materials and Methods}

\section{Bacterial strains and culture conditions}

Bacterial strains used in this study, Chromobacterium violaceum CV026 and Chromobacterium violaceum ATCC 31532 (McClean et al., 1997), were kindly provided by Professor Robert J.C. McLean, Texas State University, USA. N-Acyl-homoserine lactone (C6-HSL) was purchased from Sigma (Buchs, Switzerland), aliquoted and used at $15 \mu \mathrm{M}$ in C. violaceum CV026 cultures to induce violacein production. The bacterium was cultivated aerobically and maintained in Luria Bertani (LB) medium at $30^{\circ} \mathrm{C}$; the turbidity was measured at $620 \mathrm{~nm}$ and adjusted to match a 0.5 Mc-Farland density standard, which produces approximately $1 \times 10^{8} \mathrm{cfu} / \mathrm{mL}$ according to the Clinical and Laboratory Standards Institute (CLSI) (Choo et al., 2006; CLSI, 2009).

Bacterial strains were reactivated and plated onto LB agar, and then incubated during 18 to $24 \mathrm{~h}$ at $30^{\circ} \mathrm{C}$. Colonies were checked by macroscopic (morphology, color and consistency) and microscopic characteristics (Gram staining), and also phenotipically identified. BBL CRYSTAL Enteric/Nonfermenter (E/NF) Identification (ID) kit, from Becton \& Dickinson, was used to identify nonfermenting Gram-negative bacteria (Holmes et al., 1994). Strains were stored at $-70{ }^{\circ} \mathrm{C}$ with $80 \%$ glycerol and subcultured twice on Sabouraud agar (Difco) prior to testing anti-QS to confirm its purity and viability.

\section{Plant material and essential oils isolation}

Plant specimens were collected from several locations of Colombia. Samples were stored in the dark, transported to the laboratory, washed and used fresh with minimal light exposure. Plant material was identified by an expert botanist from the Institute of Natural Sciences at the National University of Colombia (Bogotá). A voucher of each species was deposited at the Institute's Herbarium. Essential oils were extracted by steam distillation (SD) or microwave assisted hydrodistillation (MWHD) and characterized by GC-MS using a previously reported method (Stashenko et al., 2004). Sampling sites and extraction methods for essential oils are shown in Table 1.

\section{Preparation of essential oil dilutions}

Essential oils were initially dissolved in DMSO and then added to the culture medium to obtain concentrations of $0.01,0.1,10,100,200,300 \mu \mathrm{g} / \mathrm{mL}$. The maximum concentration of DMSO used in the assays was $0.5 \%$ (Olivero et al., 2011).

\section{Measurement of cell growth}

Broth dilution method was used to determine cell growth inhibition (CLSI, 2009). Briefly, a bacterial strain CV026 inoculum was exposed to different dilutions of essential oils or pure DMSO during $18 \mathrm{~h}$ at $30^{\circ} \mathrm{C}$ (Choo et al., 
Table 1 - Essential oils from Lippia alba used in this study.

\begin{tabular}{lcccc}
\hline Code $^{\mathrm{a}}$ & Sampling site & Sample type & Extraction type & Voucher Number \\
\hline VEsrW01E & Sacabeña, Arauca & Whole plant & MWHD & 512084 \\
VEmcT02E & Anolaima, Cundinamarca & Whole plant & SD & 484650 \\
VEboW02E & Colorado, Bolívar & Whole plants & MWHD & 512272 \\
VEbgW03H & Bucaramanga, Santander & Leaves & MWHD & 512077 \\
VEbgW01E & Bucaramanga, Santander & Whole plant & MWHD & 480750 \\
\hline
\end{tabular}

Notes: ${ }^{\text {a }}$ Code assigned by CENIVAM to Lippia alba essential oils isolated in different locations or extracted using a specific method. SD: steam distillation; MWHD: microwave assisted hydrodistillation.

2006) to test their effect on cell growth. After the incubation period, the cell density was read at $620 \mathrm{~nm}$ and the absorbance data were normalized to vehicle-control, for which it was assumed $100 \%$ of cell growth. C. violaceum ATCC 31532 was used as control to ensure reproducible results.

\section{Anti-quorum sensing activity}

The assays were done as described in the methodology proposed by Choo et al. (2006) and McLean et al. (2004). Production of violacein by the mutant CV026 was possible upon external addition of C6-HSL. To investigate the inhibitory effects of $L$. alba essential oils on this process, cells were treated simultaneously with diverse concentrations of the oils and the violacein production was measured.

An overnight culture of $C$. violaceum CV026 (in LB broth, $30{ }^{\circ} \mathrm{C}$ ) was adjusted to an $\mathrm{OD}_{620}$ of 0.1 , and then $100 \mu \mathrm{L}$ of bacterial suspension was added to sterile Eppendorf tubes containing $890 \mu \mathrm{L}$ of LB media supplemented with $5 \mu \mathrm{L}$ of C6-HSL $(15 \mu \mathrm{M})$, and $5 \mu \mathrm{L}$ of essential oil to achieve final concentrations of $0.01,0.1,10,100$, 200 and $300 \mu \mathrm{g} / \mathrm{mL}$. Control tubes received $5 \mu \mathrm{L}$ of $0.5 \%$ DMSO. Tubes were covered with aluminum foil and incubated aerobically for $24 \mathrm{~h}$. The experiments were performed by triplicates.

\section{Quantification of violacein production}

The extent of violacein production by $C$. violaceum CV026 in the presence of control (DMSO) or essential oils from Lippia alba was carried out in the presence of C6HSL at a working concentration of $15 \mathrm{M}$. First, $300 \mu \mathrm{L}$ of cultures were placed in Eppendorf tubes and lysed by adding $300 \mu \mathrm{L}$ of $10 \%$ SDS, mixing for 5 seconds with vortex, and incubating at room temperature during $5 \mathrm{~min}$ (Blosser and Gray, 2000; Khan et al., 2009). This solution was then mixed with $800 \mu \mathrm{L}$ of 1-butanol/water (1:1), vortexed for 5 seconds and centrifuged at $13000 \mathrm{rpm}$ for $5 \mathrm{~min}$. The precipitate was discarded, the upper (butanol) phase containing the violacein was collected, and the absorbance was read at $585 \mathrm{~nm}$ (McLean et al., 2004; Choo et al., 2006). The violacein concentration generated in the absence of essential oil was used as positive control and all other mea- surements were normalized to this value. Each experiment was performed in triplicate.

\section{Antibacterial activity assay}

The antibacterial potential of essential oils from Lippia alba against S. aureus ATCC 25923 was performed through disk diffusion method in Mueller-Hinton agar (MHA; Difco) by following the method specified by the Clinical and Laboratory Standards Institute (CLSI, 2009). The bacterial strain $S$. aureus ATCC 25923 was cultivated in LB for reactivation. Wells (diameter of $6 \mathrm{~mm}$ ) were made on solidified agar plates. Each pure essential oil (5 and $10 \mu \mathrm{L}$ ) was loaded into the wells, and then the bacteria was inoculated over the whole surface of the agar plate (Krishnan et al., 2012). The plates were incubated during $18 \mathrm{~h}$ at $4{ }^{\circ} \mathrm{C}$ for the diffusion of the essential oils on the culture medium, and subsequently incubated under aerobic conditions at $37^{\circ} \mathrm{C}$ for additional $24 \mathrm{~h}$, followed by measuring the zone of growth inhibition (Issac Abraham et al., 2011).

\section{Gas chromatography-mass spectrometry (GC-MS) analysis}

The composition of the essential oil was obtained as previously described (Jaramillo-Colorado et al., 2011) with minor modifications. In short, $20 \mu \mathrm{L}$ of the oils were dissolved in $\mathrm{CHCl}_{2}$ to $1 \mathrm{~mL}$. One $\mu \mathrm{L}$ of the solution was injected into an Agilent Technologies 6890 Plus (Palo Alto, CA) GC coupled to an Agilent Technologies MSD 5975 selective detector mass equipped with a split/splitless injector port (1:50 split ratio), an injector Agilent 7863, and a data system HP ChemStation. The column had the following characteristics: $30 \mathrm{~m}, 0.25 \mathrm{~mm}$ i.d., and $0.25 \mu \mathrm{m}$ stationary phase with $5 \%$ phenyl poly(methylsiloxane). The oven temperature was set at $45{ }^{\circ} \mathrm{C}$ for $5 \mathrm{~min}$, then increased $4{ }^{\circ} \mathrm{C} / \mathrm{min}$ up to $150^{\circ} \mathrm{C}$ during $2 \mathrm{~min}$, then to $5^{\circ} \mathrm{C} / \mathrm{min}$ up to $250^{\circ} \mathrm{C}$ for $5 \mathrm{~min}$, and finally at $10^{\circ} \mathrm{C} / \mathrm{min}$ up to $275^{\circ} \mathrm{C}$. Helium was used as a carrier gas at $1 \mathrm{~mL} / \mathrm{min}$. Identification of compounds was based on Kováts indices (Ik) and by comparison of the mass spectra with those present in available databases. 


\section{Data analysis}

Results are presented as mean \pm standard deviation. Probit analysis was used to calculate the half maximal inhibitory concentration $\left(\mathrm{IC}_{50}\right)$, for both cell growth and $\mathrm{QS}$, defined as the concentration of essential oil that leads to a $50 \%$ reduction of cell growth as compared to vehiclecontrol, and the concentration of essential oil that leads to a $50 \%$ reduction of violacein production as compared to the amount produced by $C$. violaceum when fully induced by C6-HSL, respectively (Olivero et al., 2011). The differences between the means of the responses obtained for each tested concentration were evaluated by analysis of variance (ANOVA), after logarithmic data transformation. Comparisons against the control group were performed if significant differences between means there were found, using Dunn's test. In all cases, the normal distribution and equality of standard deviations of the means were checked using the Kolmogorov-Smirnov and Bartlett tests, respectively. In the absence of normality, mean comparisons between more than two groups were performed by Kruskal Wallys test. For all cases, the level of significance was set at $\mathrm{p}<0.01$.

\section{Results}

\section{Cell growth inhibition}

The antimicrobial activity of the Lippia alba essential oils was analyzed using C. violaceum CV026 as indicator microorganism, in order to evaluate whether the inhibition of violacein production owed to the microbial growth reduction or AHL inhibition. The results of the cell growth inhibition of CV026 induced by essential oils from L. alba are shown in Figure 1. In all cases, there is a clear concentration-response relationship. At $100 \mu \mathrm{g} / \mathrm{mL}$, the growth of CV026 varied between 53.4 and $82.6 \%$ compared to vehicle control. Greater oil concentrations produced proportional impact in cell growth, except for the essential oil containing the highest geraniol content $(9.5 \%)$ (VebgW03H), which allowed $23.5 \%$ cell growth at $200 \mu \mathrm{g} / \mathrm{mL}$, and only $15.4 \pm 0.8 \%$ at $300 \mathrm{mg} / \mathrm{mL}$ (Figure 1D).

\section{Quorum sensing inhibition}

The inhibitory activity of essential oils from Lippia alba against bacterial QS was evaluated by testing the violacein production by $C$. violaceum CV026 (Figure 1). Pigment production data normalized against cell growth $\left(\mathrm{OD}_{620}\right)$ are depicted in Figure 2. Two out of five tested essential oils presented promising QS-inhibition capabilities. The greatest QS inhibition was observed for the L. alba with the highest geranial and neral concentration (VEboW02E) (Figure 1C), followed by that with the greatest limonene and carvone contents (VEmcT02E) (Figure $1 \mathrm{~B})$, with $\mathrm{IC}_{50}$ values of $0.62(0.53-0.72)$ and 2.24 $(1.98-2.54) \mu \mathrm{g} / \mathrm{mL}$. These oils were followed in activity by
VEsrW01E (Figure 1A) and VEbgW01E (Figure 1E), which had similar QS inhibitory action, but greater than that observed for VEbgW03H, for which the QS data almost matched that for cell growth (Figure 1D). These results revealed the ability of essential oils from Lippia alba to inhibit QS. Moreover, as presented before, the anti-QS activity for these essential oils is independent from their effect on cell growth.

\section{Antibacterial activity assay}

To validate some aspects of the traditional uses of the tested bioactive products as antimicrobial agents, essential oils were tested against the bacterial human pathogen $S$. aureus. Regarding the disk diffusion assays, most of the essential oils showed broad zones of growth inhibition against $S$. aureus ATCC 25923 at 10 and $5 \mu \mathrm{L}$ of each pure essential oil (Figure 3). VEboW02E produced the maximum zone of growth inhibition ( $46 \pm 0.8 \mathrm{~mm}$ ) (Figure 3D), followed by $\mathrm{VEbgW03H}$ with $32 \pm 1.0 \mathrm{~mm}$, and VEsrW01E with $31 \pm 1.7 \mathrm{~mm}$ (Figures $3 \mathrm{~A}$ and $3 \mathrm{E}$ ). These findings show that essential oils from $L$. alba do possess antibacterial activity at tested concentrations against Grampositive bacteria such as S. aureus ATCC 25923.

\section{Lippia alba oil composition}

The GC-MS analysis of evaluated L. alba samples are presented in Table 2. The main constituents were identified as limonene, neral, carvone, geraniol, bicyclosesquitelandrene, geranial, piperitenone, $\beta$-bourbonene, and trans$\beta$-caryophyllene.

\section{Discussion}

In many Gram-negative bacteria, a number of bacterial traits, including virulence and pathogenicity, are regulated by acyl homoserine lactone (AHL)-mediated QS system (Khan et al., 2009). The quenching of bacterial cell-cell communication could be a promising strategy to attenuate the expression of virulence genes, and thus for the control of pathogenic infections (Issac Abraham et al., 2011). Although several medicinal properties of Lippia alba such as antiviral, antibacterial, antifungal and antiparasitic have been investigated so far (Stashenko et al., 2004; Hennebelle et al., 2008; Ara et al., 2009; López et al., 2011), its ability to prevent QS has been partially studied.

The results of this study revealed that, in the absence of significant effects on cell growth, essential oils from Lippia alba have the capacity to significantly inhibit a QS system based on the reduction of violacein production in CV026. Recently we have reported that two of the oils studied here (samples VEsrW01E, voucher 512084, and VEboW02E, voucher 512272) inhibited QS in a model based on sensor strains $P$. putida (pKR-C12) and E. coli (pJBA132) (Jaramillo-Colorado et al., 2011). 
(A)

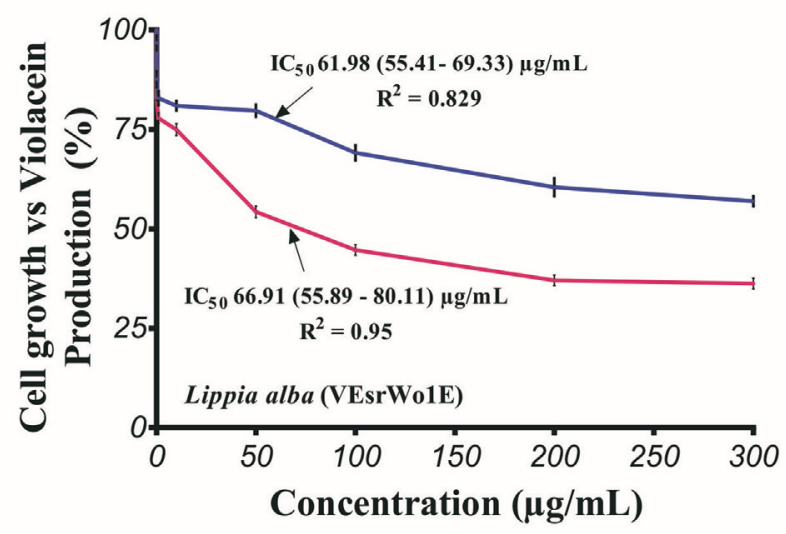

(C)

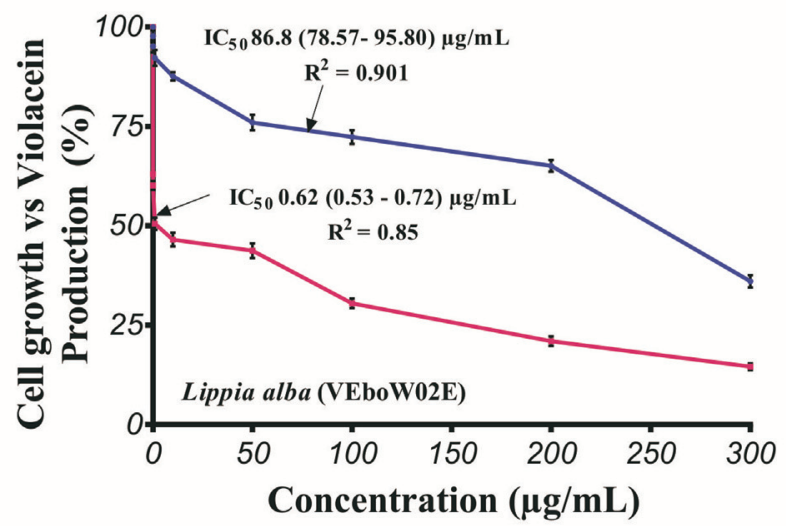

(E)

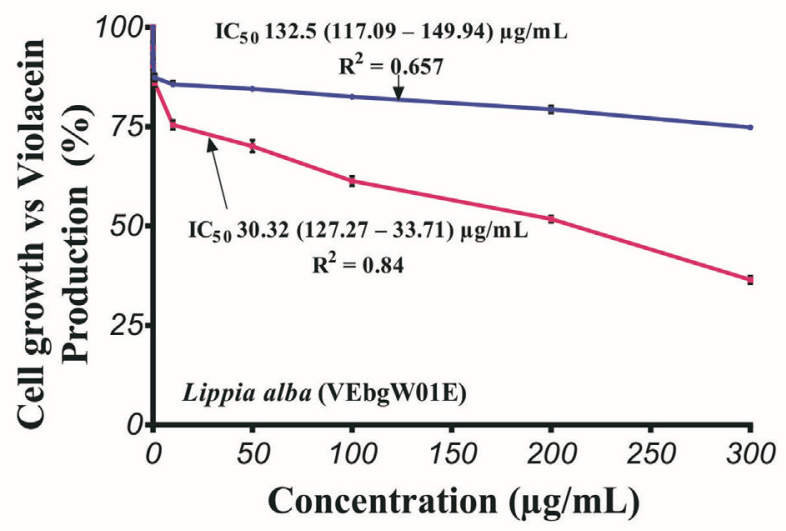

(B)

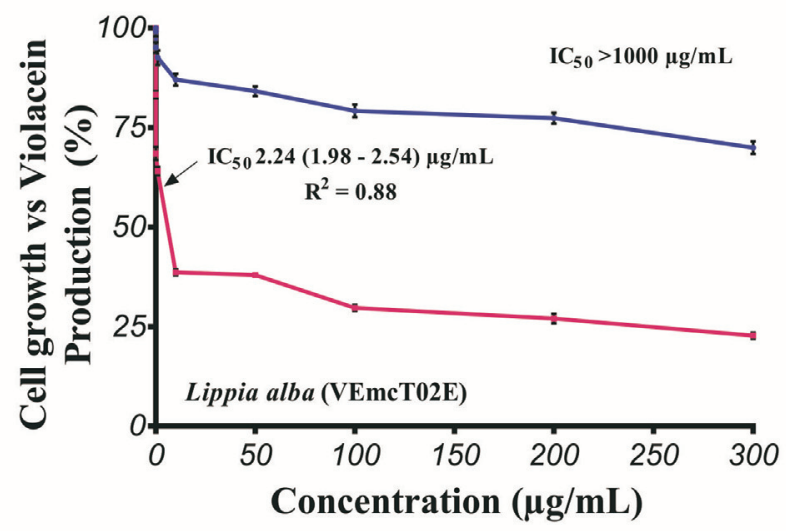

(D)

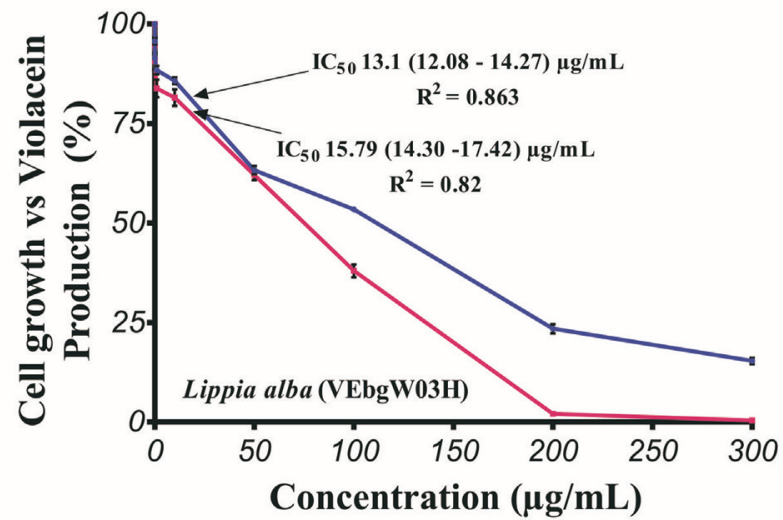

Figure 1 - Effect of essential oils from Lippia alba on cell growth and violacein production in C. violaceum CV026 exposed to essential oils. (A) VEsrWo1E; (B) VEmcTo2E; (C) VEboW02E; (D) VEbgW03H and (E) VEbgW01E. IC 50 values are presented as the mean value $(95 \%$ confidence interval). $R^{2}$ (regression coefficient) were done for probit analysis. Vertical bars represent means of three replicates \pm standard deviation.

These anti-QS properties have also been found for natural plant extracts such as that of Lotus corniculatus (Choo et al., 2006). Similarly, anti-QS compounds have also been reported for Pseudomonas aeruginosa, including molecules isolated from Pisum sativum, Conocarpus erectus, Chamaesyce hypericifolia, Callistemon viminalis,
Bucida buceras and Acalypha alopecuroidea (Musthafa et al., 2010). Szabó et al. (2010) evaluated the effect of several essential oils on bacterial growth and QS, using the sensor strain C. violaceum $\mathrm{CV} 026$, showing that rose, geranium, lavender and rosemary oils were the most potent QS inhibitors. Eucalyptus and citrus oils moderately reduced 


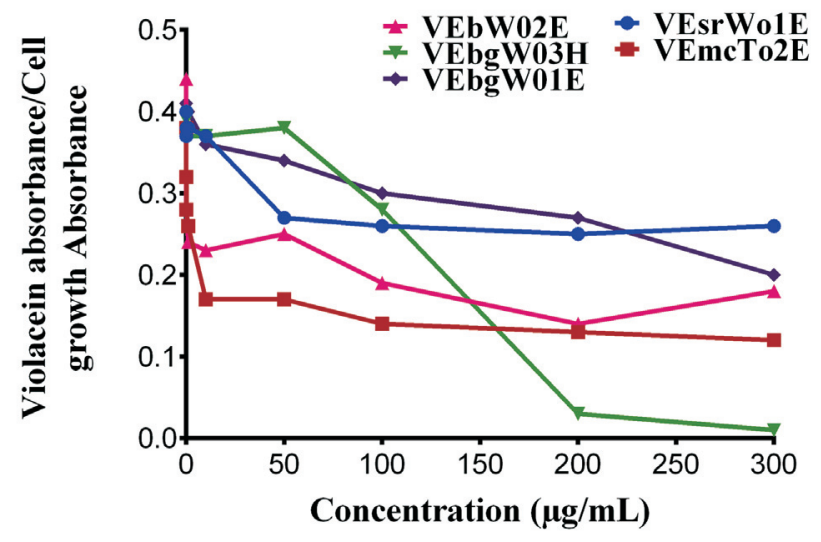

Figure 2 - Violacein production normalized against bacterial concentration $\left(\mathrm{OD}_{620}\right)$ in $C$. violaceum exposed to essential oils from Lippia alba. pigment production by CV026, whereas the chamomile, orange and juniper oils were ineffective. Choo et al. (2006) conducted studies about inhibition of QS signals with vanilla extract, being violacein production reduced by up to 87.73 and $98.41 \%$ in 1 and $2 \%$ extract, respectively; furthermore, the main chemical components of these extracts had structural similarity to the natural autoinducers or furanone derivatives.

The composition of the essential oil varies greatly, suggesting the existence of a high number of chemotypes. According to Hennebelle et al. (2008), there are at least seven chemotypes on the basis of composition and possible common biosynthetic pathways between different oils. Chemotype I had citral, linalool and $\beta$-caryophyllene, as the main constituents; chemotype II, tagetenone; the most

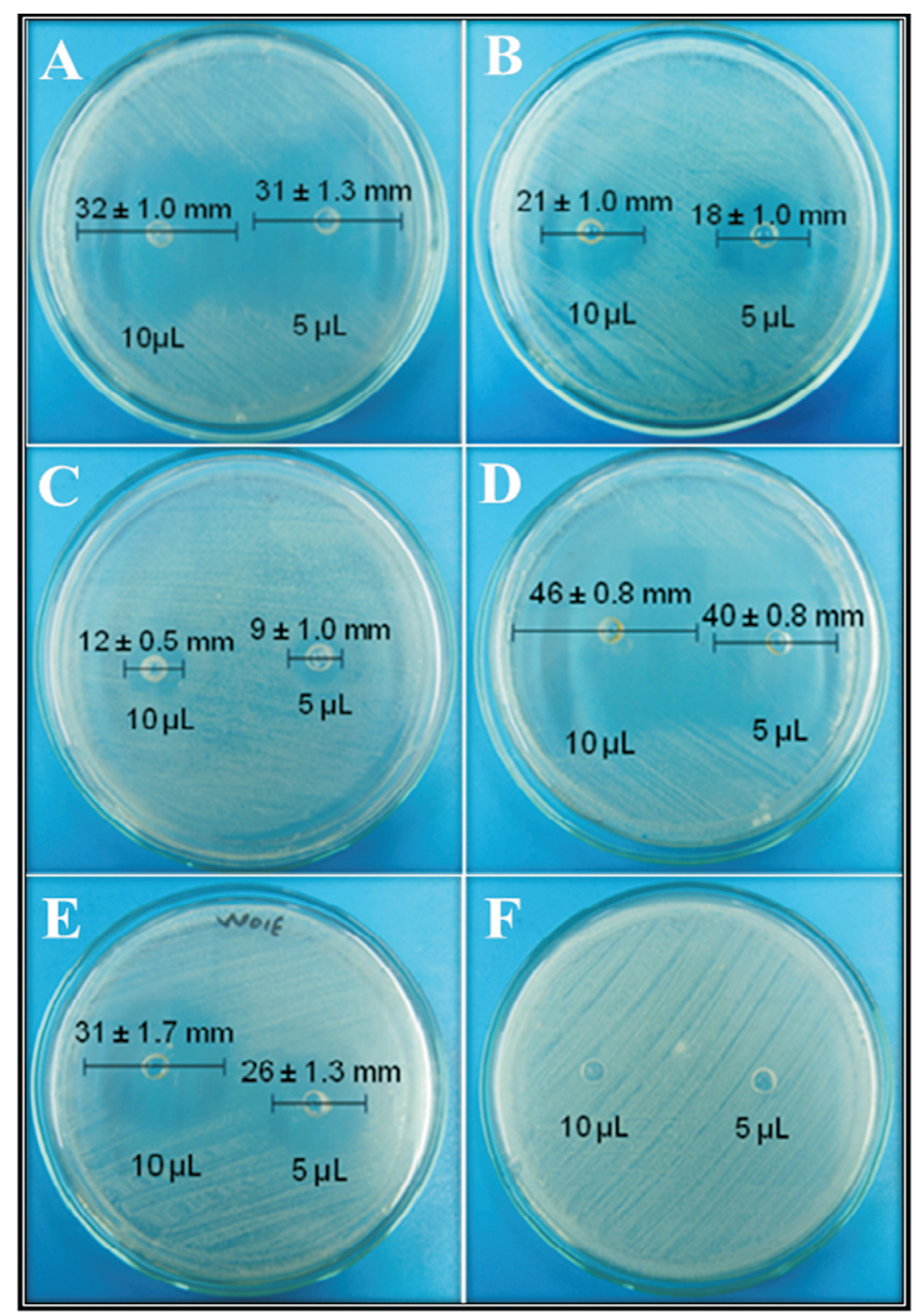

Figure 3 - Antibacterial activity of essential oils from Lippia alba on S. aureus ATCC 25923 using the agar diffusion test. (A) VEbgW03H; (B) VEbgW01H; (C) VEmcT02E; (D) VEb0W02E; (E) VEsrW01E and (F) DMSO. 
Table 2 - Major components of essential oils from Lippia alba as identified by Gas chromatography- mass spectrometry.

\begin{tabular}{|c|c|c|c|c|c|c|}
\hline \multirow[t]{2}{*}{ Components } & \multirow[t]{2}{*}{$\mathrm{I}_{\mathrm{k}} \mathrm{DB}-5$} & \multicolumn{5}{|c|}{ Essential oils from Lippia alba (\%) } \\
\hline & & VEsrW01E & VEmcT02E & VEboW02E* & VEbgW03H & VEbgW01E* \\
\hline 6-Methyl-5-hepten-2-one & 986 & 1.9 & - & 4.1 & 2.6 & - \\
\hline Limonene & $1034-1041$ & 22.4 & 37.0 & 3.2 & 3.0 & 25.8 \\
\hline Linalool & $1100-1102$ & 0.6 & 0.7 & 2.0 & 1.4 & 0.9 \\
\hline Neral & $1239-1248$ & 10.4 & - & 21.5 & 19.5 & - \\
\hline Geraniol & $1249-1258$ & - & - & 3.9 & 9.5 & - \\
\hline Carvone & $1251-1258$ & 25.3 & 27.9 & - & - & 49.6 \\
\hline Piperitone & $1260-1264$ & 1.1 & 0.1 & - & - & 3.2 \\
\hline Geranial & $1271-1277$ & 10.4 & - & 28.9 & 23.3 & - \\
\hline Piperitenone & $1343-1349$ & 2.2 & 1.6 & - & - & 6.1 \\
\hline Geranyl acetate & $1373-1379$ & 0.4 & 0 & 1.6 & 3.6 & 0 \\
\hline$\beta$-Elemene & $1385-1398$ & 1.7 & 0.1 & 0.9 & 2.2 & 0 \\
\hline$\beta$-Bourbonene & 1391 & - & 5.3 & - & - & 2.4 \\
\hline trans- $\beta$-Caryophyllene & $1430-1436$ & 2.4 & 1.4 & 7.3 & 6.6 & 0.1 \\
\hline$\beta$-Guaiene & $1442-1447$ & 1.3 & - & 1.8 & 1.1 & - \\
\hline trans- $\beta$-Farnesene & $1451-1456$ & 0.2 & 1.8 & 0.1 & 0.4 & 0.7 \\
\hline Bicyclosesquifelandrene & $1490-1496$ & 8.0 & 12.3 & 1.9 & 3.0 & 1.2 \\
\hline Caryophyllene oxide & 1596-1599 & 0.4 & - & 2.3 & 1.3 & - \\
\hline
\end{tabular}

$\mathrm{I}_{\mathrm{k}}$ DB-5: Kovats retention index for DB-5.

*: The composition of these essential oils has been previously reported (Jaramillo-Colorado et al., 2011).

common case for chemotype III were limonene and carvone or related monoterpenic ketones; chemotype IV, myrcene; chemotype V, $\gamma$-terpinene; chemotype VI camphor-1, 8-cineole and chemotype VII, estragole. Therefore, the essential oils of $L$. alba studied here were classified as citral (geranial-neral) and carvone/limonene chemotypes, thus corresponding to chemotypes I and III, respectively.

L. alba species is characterized by the variability in the chemical composition of its essential oils, which vary, as it has been presented here, according to the part of the plant employed in the distillation, the state of development, the geographic location, the characteristics of the soil, climate, and other local conditions (Stashenko et al., 2004). Most of the essential oils have one or a few major constituents and a variety of other minor components. Thus, mode of action of these mixtures on the QS system is uncertain (Khan et al., 2009), although it may be speculated that it probably involves a synergistic action of the majority and minority compounds identified in the essential oils.

To date, known mechanisms of QS inhibition include: competitive binding of signal-like molecules to cognate receptors, as in the case of furanones; enzymatic signal degradation, as seem with acyl homoserine lactone (AHL) acylases, and inhibition of reception signal molecules (Sio et al., 2006; Taganna et al., 2011). Our results have shown that essential oils are a diverse and suitable source of QS inhibitor compounds. The presence of molecules with different structures in the oils, allows a wider spectrum of bioactivity. Several studies on the essential oils from $L$. alba bioactivities have revealed their antiviral, antibacterial, antifungal and antiparasitic activities, thus sustaining their use in the treatment of diseases of microbial origin (Escobar et al., 2010; López et al., 2011). A recent report by our group has revealed the anti-QS activity of essential oils isolated from L. alba and other species. In this case, although an approach with different sensor plasmids (Jaramillo-Colorado et al., 2011) was used, similar findings were obtained, reinforcing the idea that examined essential oils do have promising action as anti-QS inhibitors.

Antiseptic activity has been a promising issue for Lippia alba. Several studies have reported the antimicrobial and antifungal activities of this essential oil extracted from two chemotypes. The carvone chemotype has been reported to be active against several microorganisms, particularly against Gram-positives strains from human clinical isolates. On the other hand, the linalool chemotype has been successfully proven against Candida albicans (Hennebelle et al., 2008; Jaramillo-Colorado et al., 2011).

Due to the high antimicrobial activity of monoterpenes and sesquiterpenes from essential oils (Oliveira et $a l ., 2006)$, it can be suggested that the antimicrobial activity of VEboW02E and VEbgW03H is probably related to the high content of oxygen-containing monoterpenes, represented mainly by aldehydes and alcohols, such as neral/geranial (Oliveira et al., 2006). 
In short, these results suggest the essential oils from Lippia alba have interesting anti-QS and antiseptic activities. Therefore, new researches must be undertaken in order to elucidate the possible mechanisms involved.

\section{Conclusion}

Essential oils from Colombian flora, specifically Lippia alba have noticeable anti-QS and antimicrobial activities, which may make them targets for the development of drugs to fight bacterial infections.

\section{Acknowledgments}

The authors thank Professor Robert J.C. McLean for providing the biosensor strains for the QS tests. This work was sponsored by the Support Program to Research Groups, Vice-presidency for Research, University of Cartagena (2012-2013).

\section{References}

Ara N, Nur MH, Amran MS, Wahid MI, Ahmed M (2009) In vitro antimicrobial and cytotoxic activities of leaves and flowers extracts from Lippia alba. Pak J Biol Sci 12:87-90.

Blosser RS, Gray KM (2000) Extraction of violacein from Chromobacterium violaceum provides a new quantitative bioassay for $\mathrm{N}$-acyl homoserine lactone autoinducers. J Microbiol Methods 40:47-55.

Chan KG, Atkinson S, Mathee K, Sam CK, Chhabra S, Camara M, Koh CL, Williams P (2011) Characterization of N-acylhomoserine lactone-degrading bacteria associated with the Zingiber officinale (ginger) rhizosphere: Co-existence of quorum quenching and quorum sensing in Acinetobacter and Burkholderia. BMC Microbiol 11:51.

Chong YM, Yin WF, Ho CY, Mustafa MR, Hadi AHA, Awang K, Narrima P, Koh CL, Appleton DR, Chan KG (2011) Malabaricone C from Myristica cinnamomea exhibits antiquorum sensing activity. J Nat Prod 74:2261-2264.

Choo JH, Rukayadi Y, Hwang JK (2006) Inhibition of bacterial quorum sensing by vanilla extract. Lett Appl Microbiol 42:637-641.

Christiaen SEA, Brackman G, Nelis HJ, Coenye T (2011) Isolation and identification of quorum quenching bacteria from environmental samples. J Microbiol Methods 87:213-219.

CLSI (2009) Métodos para Pruebas de Sensibilidad a los antimicrobianas por dilución para bacterias que crecen en condiciones aeróbicas. Eighth edition ed, Pennsylvania.

Debler EW, Kaufmann GF, Kirchdoerfer RN, Mee JM, Janda KD, Wilson IA (2007) Crystal Structures of a Quorumquenching Antibody. J Mol Biol 368:1392-1402.

Deep A, Chaudhary U, Gupta V (2011) Quorum sensing and Bacterial Pathogenicity: From Molecules to Disease. J Lab Physicians 3:4-11.

Ditu LM, Chifiriuc MC, Bezirtzoglou E, Voltsi C, Bleotu C, Pelinescu D, Mihaescu G, Lazar V (2011) Modulation of virulence and antibiotic susceptibility of enteropathogenic Escherichia coli strains by Enterococcus faecium probiotic strain culture fractions. Anaerobe 17:448-451.

Escobar P, Milena Leal S, Herrera LV, Martinez JR, Stashenko E (2010) Chemical composition and antiprotozoal activities of
Colombian Lippia spp essential oils and their major components. Mem Inst Oswaldo Cruz 105:184-190.

Hennebelle T, Sahpaz S, Joseph H, Bailleul F (2008) Ethnopharmacology of Lippia alba. J Ethnopharmacol 116:211222.

Holmes B, Costas M, Thaker T, Stevens M (1994) Evaluation of two BBL Crystal systems for identification of some clinically important gram-negative bacteria. J Clin Microbiol 32:2221-2224.

Issac Abraham SV, Palani A, Ramaswamy BR, Shunmugiah KP, Arumugam VR (2011) Antiquorum sensing and antibiofilm potential of Capparis spinosa. Arch Med Res 42:658-668.

Jaramillo-Colorado B, Olivero-Verbel J, Stashenko EE, Wagner-Döbler I, Kunze B (2011) Anti-quorum sensing activity of essential oils from Colombian plants. Nat Prod Res 26:1075-1086.

Kabir AH, Roy AG, Alam MF, Islam R (2010) Detection of Quorum Sensing Signals in Gram-Negative Bacteria by Using Reporter Strain CV026. Not Sci Biol 2:72-75.

Kaufman G (2011) Antibiotics: mode of action and mechanisms of resistance. Nurs Stand 25:49-55.

Khan MSA, Zahin M, Hasan S, Husain FM, Ahmad I (2009) Inhibition of quorum sensing regulated bacterial functions by plant essential oils with special reference to clove oil. Lett Appl Microbiol 49:354-360.

Köhler T, Perron GG, Buckling A, van Delden C (2010) Quorum sensing inhibition selects for virulence and cooperation in Pseudomonas aeruginosa. PLoS Pathog 6:1-6.

Krishnan T, Yin WF, Chan KG (2012) Inhibition of Quorum Sensing-Controlled Virulence Factor Production in Pseudomonas aeruginosa PAO1 by Ayurveda Spice Clove (Syzygium Aromaticum) Bud Extract. Sensors 12:40164030.

López MA, Stashenko EE, Fuentes JL (2011) Chemical composition and antigenotoxic properties of Lippia alba essential oils. Genet Mol Biol 34:479-488.

May AL, Eisenhauer ME, Coulston KS, Campagna SR (2011) Detection and Quantitation of Bacterial Acylhomoserine Lactone Quorum Sensing Molecules via Liquid Chromatography-Isotope Dilution Tandem Mass Spectrometry. Anal Chem 84:1243-1252.

McClean KH, Winson MK, Fish L, Taylor A, Chhabra SR, Camara M, Daykin M, Lamb JH, Swift S, Bycroft BW, Stewart GSAB, Williams P (1997) Quorum sensing and Chromobacterium violaceum: exploitation of violacein production and inhibition for the detection of $\mathrm{N}$-acylhomoserine lactones. Microbiology 143:3703-3711.

McLean RJC, Pierson Iii LS, Fuqua C (2004) A simple screening protocol for the identification of quorum signal antagonists. J Microbiol Methods 58:351-360.

Morohoshi T, Kato M, Fukamachi K, Kato N, Ikeda T (2008) $\mathrm{N}$-Acylhomoserine lactone regulates violacein production in Chromobacterium violaceum type strain ATCC 12472. FEMS Microbiol Lett 279:124-130.

Musthafa KS, Ravi AV, Annapoorani A, Packiavathy ISV, Pandian SK (2010) Evaluation of anti-quorum-sensing activity of edible plants and fruits through inhibition of the N-acylhomoserine lactone system in Chromobacterium violaceum and Pseudomonas aeruginosa. Chemotherapy 56:333-339.

Oliveira DR, Leitão GG, Santos SS, Bizzo HR, Lopes D, Alviano CS, Alviano DS, Leitão SG (2006) Ethnopharmacological 
study of two Lippia species from Oriximiná, Brazil. J Ethnopharmacol 108:103-108.

Olivero JT, Pájaro NP, Stashenko EE (2011) Antiquorum Sensing activity of essential oils isolated from different species of the genus piper. Vitae 18:77-82.

Rocha-Estrada J, Aceves-Diez A, Guarneros G, de la Torre M (2010) The RNPP family of quorum-sensing proteins in Gram-positive bacteria. Appl Microbiol Biotechnol 87:913-923.

Siddiqui MF, Sakinah M, Singh L, Zularisam AW (2012) Targeting $\mathrm{N}$-acyl-homoserine-lactones to mitigate membrane biofouling based on quorum sensing using a biofouling reducer. J Biotechnol 161:190-197.

Singh BN, Singh BR, Singh RL, Prakash D, Sarma BK, Singh HB (2009) Antioxidant and anti-quorum sensing activities of green pod of Acacia nilotica L. Food Chem Toxicol 47:778-786.

Sio CF, Otten LG, Cool RH, Diggle SP, Braun PG, Bos R, Daykin M, Cámara M, Williams P, Quax WJ (2006) Quorum Quenching by an N-Acyl-Homoserine Lactone Acylase from Pseudomonas aeruginosa PAO1. Infect Immun 74:16731682.

Sipahi OR (2008) Economics of antibiotic resistance. Expert Rev Anti-Infect Ther 6:523-539.

Stashenko EE, Jaramillo BE, Martínez JR (2004) Comparison of different extraction methods for the analysis of volatile secondary metabolites of Lippia alba (Mill.) N.E. Brown, grown in Colombia, and evaluation of its in vitro antioxidant activity. J Chromatogr A 1025:93-103.

Szabó MA, Varga GZ, Hohmann J, Schelz Z, Szegedi E, Amaral L, Molnár J (2010) Inhibition of quorum-sensing signals by essential oils. Phytother Res 24:782-786.

Taganna JC, Quanico JP, Perono RMG, Amor EC, Rivera WL (2011) Tannin-rich fraction from Terminalia catappa inhib- its quorum sensing (QS) in Chromobacterium violaceum and the QS-controlled biofilm maturation and LasA staphylolytic activity in Pseudomonas aeruginosa. J Ethnopharmacol 134:865-871.

Teplitski M, Robinson JB, Bauer WD (2000) Plants Secrete Substances That Mimic Bacterial N-Acyl Homoserine Lactone Signal Activities and Affect Population Density-Dependent Behaviors in Associated Bacteria. Mol Plant Microbe Interact 13:637-648.

Truchado P, López-Gálvez F, Gil MI, Tomás-Barberán FA, Allende A (2009) Quorum sensing inhibitory and antimicrobial activities of honeys and the relationship with individual phenolics. Food Chem 115:1337-1344.

Vattem DA, Mihalik K, Crixell SH, McLean RJC (2007) Dietary phytochemicals as quorum sensing inhibitors. Fitoterapia 78:302-310.

Whitehead NA, Barnard AML, Slater H, Simpson NJL Salmond GPC (2001) Quorum-sensing in Gram-negative bacteria. FEMS Microbiol Rev 25:365-404.

Williams P, Winzer K, Chan WC, Cámara M (2007) Look who's talking: communication and quorum sensing in the bacterial world. Philos Trans R Soc Lond B Biol Sci 362:1119-1134.

Xavier KB, Bassler BL (2003) LuxS quorum sensing: more than just a numbers game. Curr Opin Microbiol 6:191-197.

Yang L, Liu Y, Sternberg C, Molin S (2010) Evaluation of Enoyl-Acyl Carrier Protein Reductase Inhibitors as Pseudomonas aeruginosa Quorum-Quenching Reagents. Molecules 15:780-792.

Zhang LH, Dong YH (2004) Quorum sensing and signal interference: diverse implications. Mol Microbiol 53:1563-1571.

All the content of the journal, except where otherwise noted, is licensed under a Creative Commons License CC BY-NC. 